\title{
Synthesis of Branched Polystyrene by Photopolymerization of Selenium-Containing Styrene Monomer
}

\author{
Koji TAKagi, $^{\dagger}$ Yukimi NishiKawa, Tae Seok KwON, \\ Hideo KUNISADA, and Yasuo YUKI \\ Department of Materials Science and Engineering, Nagoya Institute of \\ Technology, Gokiso-cho, Showa-ku, Nagoya 466-8555, Japan
}

(Received April 12, 2000; Accepted August 18, 2000)

\begin{abstract}
KEY WORDS Branched Polystyrene/Photopolymerization/Radical Polymerization / Carbon-Selenium Bond Cleavage /
\end{abstract}

Macromolecular architecture including dendrimers and hyperbranched polymers is now receiving growing interest in both synthetic and applied polymer chemistry due to their potential application as novel functional materials. The structurally well-defined dendrimers especially enjoy recent pronounced progress; however, their synthesis often needs time-consuming protection and deprotection cycle of functional groups and rigorous purification. Hyperbranched polymers contain structural defects but exhibit properties analogous to those of dendrimers and the synthetic process is, to be emphasized, simple to easily prepare large quantity. Various type of hyperbranched polymers ${ }^{1}$ have been synthesized from monomers having $\mathrm{AB}_{\mathrm{n}}(\mathrm{n} \geqq 2)$ structure, in which the step-growth polymerization proceeds by the reaction of $A$ with B to form stable covalent bonds. Recently, selfcondensing vinyl polymerization (SCVP) of $\mathrm{AB}$ type monomer based on cationic, ${ }^{2}$ radical, ${ }^{3}$ and group transfer polymerization (GTP) ${ }^{4}$ systems have been developed to afford many hyperbranched polymers. At the initiation step, the pendant group B can be activated by the catalyst, such as $\mathrm{SnCl}_{4}$ (cationic polymerization), $\mathrm{CuCl}$ (radical polymerization), and nucleophilic reagent (GTP), to react with vinyl group of other molecules. Thus generated dimer has two reactive centers, viz., one is an original pendant group $\mathrm{B}^{*}$ and another is a newly formed $\mathrm{B}^{\dagger}$, together with one double bond (Scheme 1). Both $\mathrm{B}^{*}$ and $\mathrm{B}^{\dagger}$ are possible to bring about further reaction with the vinyl group of other dimers and the continuous reaction leads to the objective hyperbranched polymer.

We have recently reported the radical polymerization of styrene utilizing benzylphenyl selenide (BPSe) as an initiator under ultraviolet (UV) irradiation, ${ }^{5}$ where the phenylseleno group can be well introduced at the propagating end of the polymer chain. The isolated selenium end-functionallized polystyrene was found to re-initiate the photopolymerization of styrene supporting the stability of the carbon-selenium bond. The polymerization was considered to proceed via the reversible cleavage of the carbon--selenium bond ${ }^{6}$ by UV irradiation. Herein, the synthesis of branched polystyrene will be described by the photopolymerization of $p$-(phenylselenomethyl) styrene (PSeMS) that can be prepared in one pot from

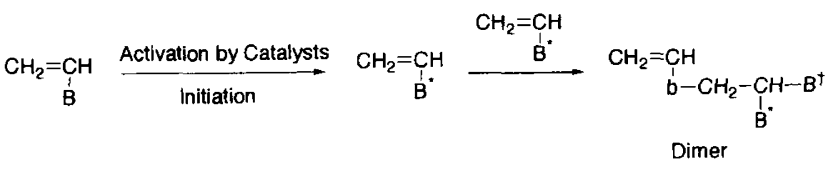

Scheme 1.

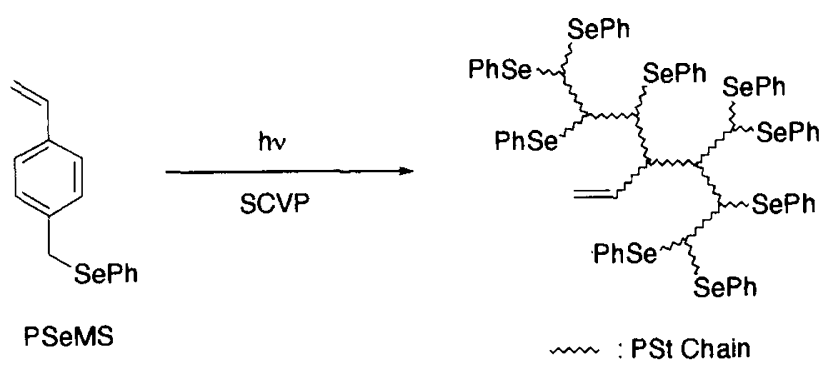

Scheme 2.

commercially available vinylbenzyl chloride (Scheme 2). PSeMS has an aforementioned $A B$ type structure, namely $A$ and $B$ denote the vinyl group and the selenium moiety, respectively.

\section{EXPERIMENTAL}

\section{Instruments}

${ }^{1} \mathrm{H}$ Nuclear magnetic resonance (NMR) spectra were recorded in $\mathrm{CDCl}_{3}$ on a JEOL GX-400 spectrometer (tetramethylsilane as an internal standard). ${ }^{77} \mathrm{Se}$ NMR spectra were recorded in $\mathrm{CDCl}_{3}$ on a VARIAN UNITY plus-400 spectrometer (diphenyl diselenide as an external standard). Infrared (IR) spectra were obtained on a NICOLET Impact-400 D spectrophotometer. Melting points were determined on a YANAGIMOTO micro melting point apparatus. Elemental analyses were performed by a Yanaco CHN CORDER MT-3 analyzer. Gel permeation chromatographic (GPC) analyses were carried out on a Tosoh DP-8020 (TSK gel Multipore $\mathrm{H}_{\mathrm{XL}}-\mathrm{M}$, tetrahydrofuran (THF) as an eluent) on the basis of standard polystyrene samples. 


\section{Materials}

Vinylbenzyl chloride, bromobenzene, 1-chloroethylbenzene, and 1-bromo-4-t-butylbenzene for the synthesis of PSeMS, 1-(4-t-butylphenyl)selenoethylbenzene (a model compound ), and $p$-( ( 4-t-butylphenyl ) selenomethyl ) styrene (BPSeMS) were used as received. Benzoyl peroxide (BPO) and 2,2'-azobisisobutyronitrile (AIBN) were recrystallized from EtOH. THF was dried over Na/benzophenone and distilled under nitrogen. Benzene was dried over $\mathrm{P}_{2} \mathrm{O}_{5}$ followed by $\mathrm{CaH}_{2}$ and distilled under nitrogen. All other reagents were used as received.

\section{Synthesis of Monomers and a Model Compound}

To a THF solution ( $100 \mathrm{~mL}$ ) of phenylmagnesium bromide $(0.10 \mathrm{~mol})$, prepared from $\mathrm{Mg}(2.4 \mathrm{~g}, 0.10 \mathrm{~mol})$ and bromobenzene $(15.7 \mathrm{~g}, 0.10 \mathrm{~mol})$, was slowly added Se $(7.1 \mathrm{~g}, 0.09 \mathrm{~mol})$ at room temperature in $0.5 \mathrm{~h}$ under nitrogen and the reaction mixture was further stirred for $0.5 \mathrm{~h}$. Subsequently, vinylbenzyl chloride ( $13.7 \mathrm{~g}, 0.09$ $\mathrm{mol}$ ) in THF (20 mL) was added dropwise and the reaction was conducted for $12 \mathrm{~h}$. After pouring the reaction mixture into cold aqueous $\mathrm{NH}_{4} \mathrm{Cl}$, the mixture was extracted with $\mathrm{Et}_{2} \mathrm{O}(\times 3)$ and the combined organic layer was dried over $\mathrm{MgSO}_{4}$. The product was purified by recrystallization from EtOH to give $4.92 \mathrm{~g}$ ( $20 \%$ yield) of PSeMS as a white needle: $\mathrm{mp} 64-67^{\circ} \mathrm{C}$. IR (KBr) 1625 , $990,904,848,730$, and $691 \mathrm{~cm}^{-1}$. ${ }^{1} \mathrm{H}$ NMR $\left(\mathrm{CDCl}_{3}, 400\right.$ $\mathrm{MHz}) \delta 4.08\left(-\mathrm{CH}_{2} \mathrm{Se}^{-}, \mathrm{s}, 2 \mathrm{H}\right), 5.19\left(\mathrm{H}_{2} \mathrm{C}=, \mathrm{d}, J=12\right.$ $\mathrm{Hz}, 1 \mathrm{H}), 5.68\left(\mathrm{H}_{2} \mathrm{C}=\mathrm{d}, J=16 \mathrm{~Hz}, 1 \mathrm{H}\right), 6.63(=\mathrm{CH}-$, $\mathrm{dd}, J=12 \mathrm{~Hz}, 16 \mathrm{~Hz}, 1 \mathrm{H}), 7.13-7.46(\mathrm{Ar}, 9 \mathrm{H}) .{ }^{77} \mathrm{Se}$ NMR $\left(\mathrm{CDCl}_{3}, 76.3 \mathrm{MHz}\right) \delta 379.0$. Anal. Calcd for $\mathrm{C}_{15} \mathrm{H}_{14}$ Se: C, 65.94; H, 5.16. Found : C, 66.17; H, 5.25. BPSeMS and 1-(4-t-butylphenyl)selenoethylbenzene were similarly synthesized.

BPSeMS: Yield $13 \% . \mathrm{mp} 64-66^{\circ} \mathrm{C}$. IR ( $\left.\mathrm{KBr}\right) 1627$, 1496, 1361, 1008, 989, 844, and $813 \mathrm{~cm}^{-1} .{ }^{1} \mathrm{H}$ NMR $\left(\mathrm{CDCl}_{3}, 400 \mathrm{MHz}\right) \delta 1.30\left(-\mathrm{C}\left(\mathrm{CH}_{3}\right)_{3}, \mathrm{~s}, 9 \mathrm{H}\right), 4.07\left(-\mathrm{CH}_{2^{-}}\right.$ $\left.\mathrm{Se}^{-}, \mathrm{s}, 2 \mathrm{H}\right), 5.19\left(\mathrm{H}_{2} \mathrm{C}=, \mathrm{d}, J=11 \mathrm{~Hz}, 1 \mathrm{H}\right), 5.69\left(\mathrm{H}_{2} \mathrm{C}=\right.$, $\mathrm{d}, J=18 \mathrm{~Hz}, 1 \mathrm{H}), 6.63\left(=\mathrm{CH}^{-}, \mathrm{dd}, J=11 \mathrm{~Hz}, 18 \mathrm{~Hz}\right.$, $1 \mathrm{H}), 7.14-7.40(\mathrm{Ar}, 8 \mathrm{H}) .{ }^{77} \mathrm{Se} \mathrm{NMR}\left(\mathrm{CDCl}_{3}, 76.3 \mathrm{MHz}\right) \delta$ 366.0. Anal. Calcd for $\mathrm{C}_{19} \mathrm{H}_{22}$ Se: C, 69.29; $\mathrm{H}, 6.73$. Found : C, 69.40; H, 6.84.

1(4-t-butylphenyl)selenoethylbenzene: Yield $19 \%$ (purified by silica gel chromatography ( $n$-hexane as an eluent), pale yellow oil). IR (neat) 1271, 1110, 1016, 822, 766,695 and $\mathrm{cm}^{-1} .{ }^{1} \mathrm{H} \mathrm{NMR}\left(\mathrm{CDCl}_{3}, 400 \mathrm{MHz}\right) \delta 1.29(-$ $\left.\mathrm{C}\left(\mathrm{CH}_{3}\right)_{3}, \mathrm{~s}, 9 \mathrm{H}\right), 1.73\left(-\mathrm{CH}_{3}, \mathrm{~d}, J=7 \mathrm{~Hz}, 3 \mathrm{H}\right), 4.41$ (> $\left.\mathrm{CHSe}^{-}, \mathrm{q}, J=7 \mathrm{~Hz}, 1 \mathrm{H}\right), 7.18-7.38(\mathrm{Ar}, 9 \mathrm{H}) .{ }^{77} \mathrm{Se} \mathrm{NMR}$ $\left(\mathrm{CDCl}_{3}, 76.3 \mathrm{MHz}\right) \delta$ 462.9. Anal. Calcd for $\mathrm{C}_{18} \mathrm{H}_{22} \mathrm{Se}: \mathrm{C}$, 68.13; H, 6.99. Found : C, 67.95; H, 7.03.

\section{Thermalpolymerization of PSeMS with AIBN}

To a Pyrex tube containing a stirrer bar was added AIBN (0.985 mg, $6.0 \mu \mathrm{mol})$, PSeMS $(0.164 \mathrm{~g}, 0.6 \mathrm{mmol})$, and benzene $(0.24 \mathrm{~mL})$. The mixture was degassed several times by freeze-pump-thaw cycles, sealed under vacuum, and the polymerization was carried out in an oil bath at $60^{\circ} \mathrm{C}$ for $46 \mathrm{~h}$. The content was poured into $\mathrm{MeOH}$ and the product was purified by reprecipitation into $\mathrm{MeOH}(\times 2)$ to give $0.136 \mathrm{~g}(83 \%)$ of poly(PSeMS) after drying in vacuo. ${ }^{1} \mathrm{H} \mathrm{NMR}\left(\mathrm{CDCl}_{3}, 400 \mathrm{MHz}\right) \delta 0.07$ -1.90 (main chain, $3 \mathrm{H}), 3.98\left(-\mathrm{CH}_{2} \mathrm{Se}^{-}, 2 \mathrm{H}\right), 6.33-7.33$ $(\mathrm{Ar}, 9 \mathrm{H}) .{ }^{77} \mathrm{Se} \mathrm{NMR}\left(\mathrm{CDCl}_{3}, 76.3 \mathrm{MHz}\right) \delta 368.0$.
Table I. Thermalpolymerization of PSeMS in benzene $(2.5 \mathrm{M})$ for $46 \mathrm{~h}$

\begin{tabular}{|c|c|c|c|c|c|}
\hline Run & Initiator & Temp. $/{ }^{\circ} \mathrm{C}$ & Yield $/ \%^{\text {a }}$ & $M_{\mathrm{n}}{ }^{b}$ & $M_{\mathrm{w}} / M_{\mathrm{n}}{ }^{b}$ \\
\hline 1 & $\operatorname{AIBN}(1 \mathrm{~mol} \%)$ & 60 & 83 & 16200 & 4.52 \\
\hline 2 & BPO(1 mol\%) & 90 & 16 & 3300 & 1.58 \\
\hline 3 & None & 60 & 6 & 5400 & 1.76 \\
\hline 4 & None & 90 & 20 & 4700 & 1.97 \\
\hline $5^{c}$ & AIBN $(1 \mathrm{~mol} \%)$ & 60 & 88 & 32100 & 3.98 \\
\hline
\end{tabular}

PSt standard). ' 'Styrene was used as a monomer.

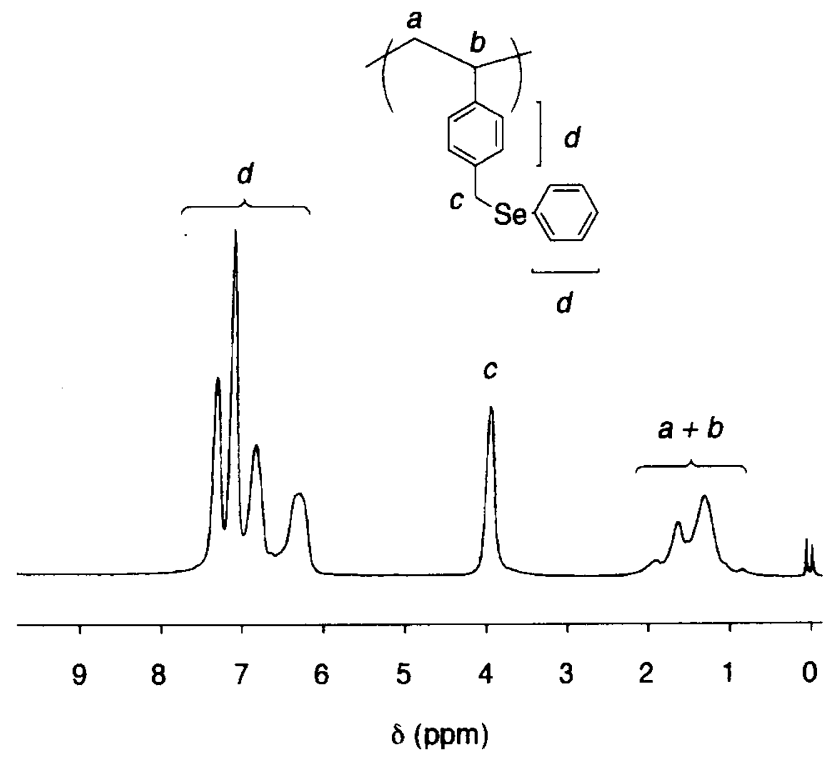

Figure 1. ${ }^{1} \mathrm{H}$ NMR spectrum (400 $\mathrm{MHz}, \mathrm{CDCl}_{3}$ ) of poly(PSeMS) obtained with AIBN initiator $\left(M_{\mathrm{n}}=16200, M_{\mathrm{w}} / M_{\mathrm{n}}=4.52\right)$.

\section{Photopolymerization of PSeMS}

Likewise, a benzene solution (2.5 M) of PSeMS ( 0.164 g, $0.6 \mathrm{mmol}$ ) in a Pyrex tube containing a stirrer bar was degassed and sealed under vacuum. The tube was then irradiated with the output of a Riko $100 \mathrm{~W}$ high-pressure mercury lamp at an $8 \mathrm{~cm}$ distance at room temperature. After the polymerization for $46 \mathrm{~h}$, the content was poured into $\mathrm{MeOH}$ and purified to give $0.07 \mathrm{~g} \mathrm{(44 \% )}$ of poly(PSeMS) after drying in vacuo. ${ }^{1} \mathrm{H} \mathrm{NMR}\left(\mathrm{CDCl}_{3}, 400\right.$ $\mathrm{MHz}) \delta$ 0.07-3.47 (main chain, $4.2 \mathrm{H}), 4.05\left(-\mathrm{CH}_{2} \mathrm{Se}^{-}\right.$ and $\left.>\mathrm{CHSe}^{-}, 1.4 \mathrm{H}\right), 5.15\left(\mathrm{H}_{2} \mathrm{C}=, 0.1 \mathrm{H}\right), 5.65\left(\mathrm{H}_{2} \mathrm{C}=\right.$, $0.1 \mathrm{H}), 6.00-7.57(\mathrm{Ar}, 9.0 \mathrm{H}) .{ }^{77} \mathrm{Se} \mathrm{NMR}\left(\mathrm{CDCl}_{3}, 76.3\right.$ $\mathrm{MHz}) \delta 372,464$. Photopolymerization of BPSeMS was similarly carried out. Poly(BPSeMS): ${ }^{77} \mathrm{Se}$ NMR $\left(\mathrm{CDCl}_{3}, 76.3 \mathrm{MHz}\right) \delta 359$.

\section{RESULTS AND DISCUSSION}

\section{Thermalpolymerization of PSeMS with Radical Initiators}

The radical polymerization of PSeMS was performed using AIBN and BPO $(1 \mathrm{~mol} \%)$ as an initiator at $60^{\circ} \mathrm{C}$ and $90^{\circ} \mathrm{C}$, respectively (Table I). In consistency with previous reports by Okamoto et al., ${ }^{7} \mathrm{BPO}$ initiated radical polymerization of PSeMS did not successfully proceed (run 2). The oxidative addition of the benzoyloxy radical to selenium was expected to occur to form a tetravalent selenium species rather than the addition to the double bond at the beginning of the polymerization. On the contrary, the polymerization with AIBN well progressed to give rise to poly(PSeMS) in $83 \%$ yield (run 1 ). It was 
Table II. Photopolymerization of PSeMS in benzene (2.5 M) with a high pressure mercury lamp

\begin{tabular}{ccccc}
\hline Run & Time $/ \mathrm{h}$ & Yield $/ \%{ }^{\mathrm{a}}$ & $M_{\mathrm{n}}{ }^{b}$ & $M_{\mathrm{w}} / M_{\mathrm{n}}{ }^{b}$ \\
\hline 1 & 20 & 36 & 1400 & 1.58 \\
2 & 46 & 44 & 1900 & 1.87 \\
3 & 66 & 49 & 2200 & 2.07 \\
\hline
\end{tabular}

${ }^{a}$ Isolated yield after reprecipitation into $\mathrm{MeOH} .{ }^{\mathrm{b}} \mathrm{GPC}(\mathrm{THF}, \mathrm{PSt}$ standard).

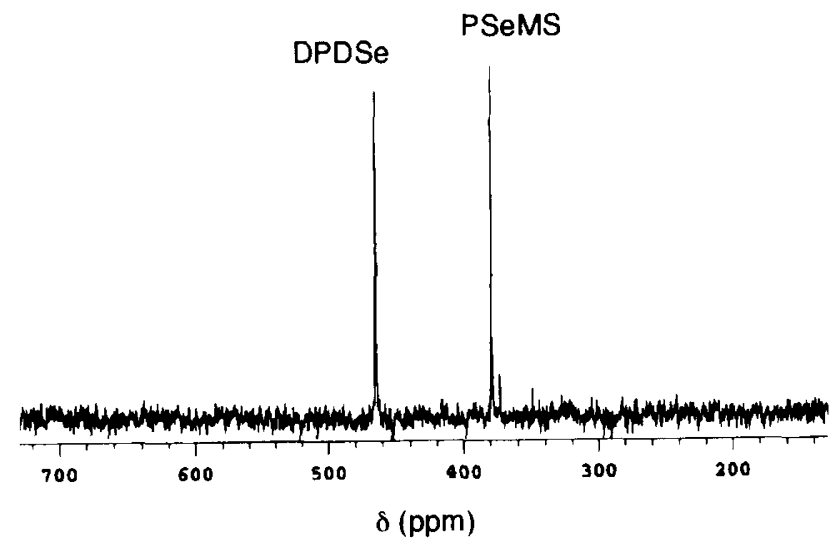

Figure 2. ${ }^{77} \mathrm{Se} \mathrm{NMR}$ spectrum $\left(76.3 \mathrm{MHz}, \mathrm{CDCl}_{3}\right)$ of a $\mathrm{MeOH}$ soluble part obtained by precipitating the polymer solution after the photopolymerization for $46 \mathrm{~h}$.

considered that the polymerization was triggered not by any radical species generated from the decomposition of PSeMS but by the conventional carbon radical from AIBN. Because the control thermal polymerization experiment in the absence of AIBN at $60^{\circ} \mathrm{C}$ afforded a polymer in very low yield ( $6 \%$ ), the carbon-selenium bond in PSeMS was supposed to be thermally stable, although the polymerization at $90^{\circ} \mathrm{C}$ brought about the polymerization to some extent (runs 3 and 4 ).

The chain transfer to the selenium moiety ${ }^{8}$ in this radical polymerization system cannot be ignored since the molecular weight distribution of poly(PSeMS) was broader $\left(M_{\mathrm{w}} / M_{\mathrm{n}}=4.52\right)$ compared with that of polystyrene obtained under the same condition $\left(M_{\mathrm{w}} / M_{\mathrm{n}}=\right.$ 3.98) (run 5). The most probable explanation may be that the chain transfer to selenium in the polymer backbone forms multifunctional macroinitiator that randomly reacts with the monomer. Judging from the ${ }^{1} \mathbf{H}$ NMR spectrum of poly(PSeMS) (Figure 1), however, the integral ratio of aliphatic protons assignable to the polymer main chain $(a+b)$ to methylene protons adjacent to selenium $(c)$ was approximately calculated to be $3: 2$, which indicated that the vinyl polymerization fundamentally occurred.

\section{Photopolymerization of PSeMS}

A stirred benzene solution of PSeMS (2.5 M) was irradiated with a high-pressure mercury lamp at room temperature to perform the photopolymerization. In our previous report, ${ }^{5}$ the benzyl carbon-selenium bond in BPSe were supposed to be homolysized ${ }^{6}$ by UV irradiation to induce the radical polymerization of styrene. Accordingly, the benzyl radical was generated from PSeMS by UV irradiation to attack the double bond of other molecules and therefore PSeMS was expected to function as "inimer" to result in the hyperbranched polystyrene. (a)
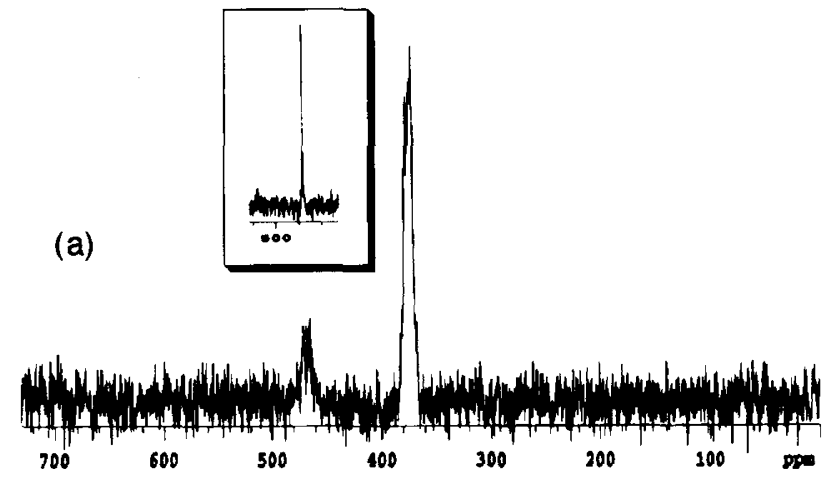

(b)

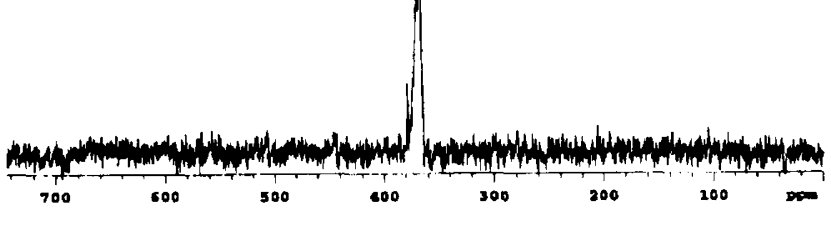

(c)

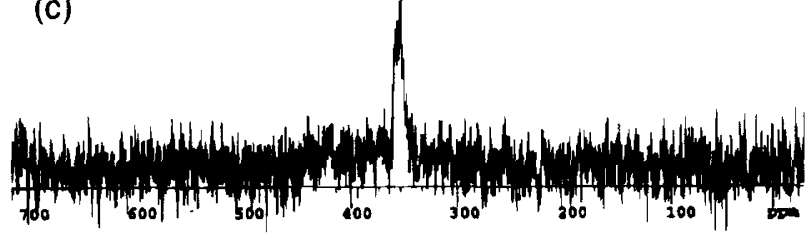

$\delta(\mathrm{ppm})$

Figure 3. ${ }^{77} \mathrm{Se} \mathrm{NMR} \mathrm{spectra}\left(76.3 \mathrm{MHz}, \mathrm{CDCl}_{3}\right.$ ) of (a) photopolymerized poly(PSeMS) $\left(M_{\mathrm{n}}=3500\right)$, (b) poly(PSeMS) obtained with AIBN initiator $\left(M_{\mathrm{n}}=6000\right)$, and (c) photopolymerized poly(BPSeMS) $\left(M_{\mathrm{n}}=3300\right)$. The inset in the section (a) represents a partial spectrum of 1-(4-t-butylphenyl)selenoethylbenzene.

Although poly(PSeMS) $\left(M_{\mathrm{n}}=1900\right)$ was obtained in 44 $\%$ isolated yield after the polymerization for $46 \mathrm{~h}$ (Table II, run 2), the polymer yield and the molecular weight $\left(M_{\mathrm{n}}\right)$ did not satisfactory increase even after the prolonged reaction period. The isolated yield was almost comparable $(49 \%)$ when the polymerization was performed for $66 \mathrm{~h}$ (run 3 ).

In the ${ }^{77} \mathrm{Se}$ NMR spectrum of a $\mathrm{MeOH}$ soluble part obtained by precipitating the polymerization mixture after $46 \mathrm{~h}$, a peak assignable to diphenyl diselenide (DPDSe) was detected at $465 \mathrm{ppm}$ in addition to that of unreacted PSeMS (379 ppm) (Figure 2). We have already demonstrated that DPDSe could effectively work as a chain transfer reagent in the polymerization of styrene to modulate the polymerization rate and the polymer molecular weight. ${ }^{10}$ There are two possibilities for the formation of DPDSe. On one hand, DPDSe could be obtained by the combination of phenylseleno radicals directly released from the monomer. On the other hand, phenylseleno radicals could be provided from the closely approached propagating end in the branched poly(PSeMS) to give DPDSe. The polymer molecular weight clearly increased to $M_{\mathrm{n}}=3500\left(M_{\mathrm{w}} / M_{\mathrm{n}}=3.57\right)$ when poly(PSeMS) $\left(M_{\mathrm{n}}=1300, M_{\mathrm{w}} / M_{\mathrm{n}}=2.09\right)$ was purified by the repeated precipitation process to exclude a con- 
taminated DPDSe and subsequently irradiated for $20 \mathrm{~h}$. Consequently, DPDSe produced in situ was proved to inhibit the smooth polymerization of PSeMS. The broad molecular weight distribution of poly(PSeMS) is rational because the growing branched polymer has a large number of reactive centers in contrast to a linear counterpart and therefore randomly reacts with the monomer.

In the ${ }^{1} \mathrm{H}$ NMR spectrum of poly(PSeMS) $\left(M_{\mathrm{n}}=3500\right)$, olefinic protons were detected at $5.15 \mathrm{ppm}$ and $5.65 \mathrm{ppm}$. The molecular weight of dendritic polymers was often underestimated in the GPC analysis due to the smaller hydrodynamic volume; on the other hand, we have also experienced that polymers containing selenium tend to be excessively evaluated. The MALDI-TOF-Mass measurement also did not show the absolute molecular weight due to the fragmentation of the phenylseleno group during the ionization. ${ }^{11}$ Hence, the accurate molecular weight and double bond-content of the branched poly(PSeMS) could not be determined. A broad peak at $464 \mathrm{ppm}$ in the ${ }^{77} \mathrm{Se}$ NMR spectrum (Figure 3a) obviously proposed the branched structure of poly(PSeMS) judging from a reference peak at $463 \mathrm{ppm}$ of a model compound, 1-(4-t-butylphenyl)selenoethylbenzene (inset in Figure 3a). A peak at $372 \mathrm{ppm}$ indicated linear structure and the integral ratio of peak at $464 \mathrm{ppm}$ to 372 ppm was calculated to be $1: 2.94$. The ${ }^{77}$ Se NMR spectrum suggested that the degree of branching was $25 \%$ which agreed with a report ${ }^{12}$ describing that the statistical process of SCVP should involve a linear component leading to the degree of branching $<0.5$. However, the present result includes some errors because the ${ }^{77} \mathrm{Se}$ NMR spectrum was measured by the proton noise decoupling method. In sharp contrast to the photopolymerization of PSeMS, the branched structure was not recognized in poly(PSeMS) obtained with AIBN initiator (Figure $3 \mathrm{~b}$ ). The photopolymerization of BPSeMS also provided a linear polymer because only one peak at 359 ppm was detected in the ${ }^{77} \mathrm{Se} \mathrm{NMR} \mathrm{spectrum} \mathrm{(Figure} \mathrm{3c).}$ These results consequently express that both the polymerization condition and the monomer character distinctly change the structure of polystyrene. Since the degree of branching is unsatisfactory probably due to the higher energy for the selenium cleavage from the primary carbon than that from the secondary carbon, the photopolymerization of $p$-(1-phenylselenoethyl)styrene is now under investigation.
Acknowledgments. This work was financially supported by the Grant-in-Aid for Scientific Research (No. 10650865) from the Ministry of Education, Science, Sports, and Culture of Japan.

\section{REFERENCES}

1. a) O. W. Webster and Y. H. Kim, J. Am. Chem. Soc., 112, 4592 (1990). b) Idem, Macromolecules, 25, 5561 (1992). c) J. M. J. Fréchet, C. J. Hawker, and R. Lee, J. Am. Chem. Soc., 113, 4583 (1991). d) A. Hult, E. Malmstrom, and M. Johansen, J. Polym. Sci., Polym. Chem. Ed., 31, 619 (1993). e) L. J. Mathias and T. W. Carothers, J. Am. Chem. Soc., 113, 4043 (1991).

2. J. M. J. Fréchet, M. Henmi, I. Gitsov, S. Aoshima, M. Leduc, and R. B. Grubbs, Science, 269, 1080 (1995).

3. a) S. G. Gaynor, S. Edelman, and K. Matyjaszewski, Macromolecules, 28, 6381 (1995). b) Idem, Macromolecules, 29, 1079 (1996). c) C. J. Hawker, J. M. J. Fréchet, R. B. Grubbs, and J. Dao, J.Am. Chem. Soc., 117, 10763 (1995).

4. a) P. F. W. Simon, W. Radke, and A. H. E. Müller, Makromol. Chem., Rapid Commun., 18, 865 (1997). b) K. Sakamoto, T. Aimiya, and M. Kira, Chem. Lett., 1997, 1245.

5. T. S. Kwon, S. Kondo, H. Kunisada, and Y. Yuki, Polym. J., 7, 559 (1998).

6. a) J. Y. C. Chu, D. G. Marsh, and W. H. H. Günther, J. Am. Chem. Soc., 97, 4905 (1975). b) A. Ouchi and Y. Koga, J. Org. Chem., 62, 7376 (1997).

7. a) Y. Okamoto, R. Homsany, and T. Yano, Tetrahedron Lett., 25, 2529 (1972). b) Y. Okamoto, K. L. Chellappa, and R. Homsany, J. Org. Chem., 38, 3172 (1973).

8. a) M. C. Fong and C. H. Schiesser, Tetrahedron Lett., 34, 4347 (1993). b) J. E. Lynos, C. H. Schiesser, and K. Sutej, $J$. Org. Chem., 58, 5632 (1993). c) C. H. Schiesser and K. Sutej, Chem. Commun., 1992, 57.

9. A. H. E. Müller, D. Yan, and M. Wulkow, Macromolecules, 30, 7015 (1997).

10. T. S. Kwon, S. Kondo, H. Kunisada, and Y. Yuki, Eur. Polym. $J$. , in press.

11. C. B. Jascieczek, D. M. Haddelton, A. J. Shooter, A. Buzy, K. R. Jennings, and R. T. Gallagher, Polym. Prepr., Am. Chem. Soc., Div. Polym. Chem., 37, 845 (1996).

12. D. Yan, A. H. E. Müller, and K. Matyjaszewski, Macromolecules, 30, 7024 (1997). 